Case Report

\title{
SURGICAL TREATMENT OF COMPLEX CROUZON SYNDROME CRANIOSYNOSTOSIS
}

\author{
Aleksandra Zdravković, Bojana Živković, Mirko Mićović, Lukas Rasulić \\ Clinic of Neurosurgery, Clinical Center of Serbia, University of Belgrade, Belgrade, Serbia
}

\begin{abstract}
Crouzon syndrome is one of the most common syndromic craniosynostosis. We present complex course of treatment in a child with Crouzon syndrome presented with multisuture craniosynostosis and hydrocephalus. A 3-monthsold boy was admitted with clinical signs of hydrocephalus and turribrachycephaly. Firstly, the hydrocephalus was addressed. The ventriculoperitoneal shunt with programmable valve was implanted. Secondly, in May 2017, posterior calvarial remodeling was done. Finally, after the child recovered, anterior calvarial remodeling with fronto-orbital advancement was performed. This completed the calvarial remodeling in this patient. Child is doing well, so far completing milestones of child development in time. This case presents an extremely complex case of syndromic multisuture craniosynostosis, in which it was necessary to perform the entire calvarial remodeling to correct the deformity and to provide a chance to the brain to grow and develop without constrictions.
\end{abstract}

Key words: Crouzon syndrome, craniosynostosis, hydrocephalus, surgical treatment.

\section{Introduction}

Crouzon syndrome was described in 1912 by neurologist Louis Crouzon. It is one of the most commonsyndromic craniosynostosis [1]. It is a genetic disorder with autosomal dominant inheritance, including more than 30 mutation of gene FGFR2 (fibroblast growth factor receptor 2) [2]. Clinically, it is presented with craniosynostosis and facial hypoplasia. The craniosynostos is usually involves multiple sutures. The facial appearance is caused by underdeveloped maxilla that is responsible for typical phenotype-hypertelorism, exophthalmos, and short nose. Eye closing can be difficult in prominent exophthalmos while breathing difficulties occur due tomaxilla deformity. Interestingly, children with this disorder are usuallyof normal intelligence [2-4].

We present complex course of treatment in a child with Crouzon syndrome presented with multisuture craniosynostosis and hydrocephalus.

\section{Case presentation}

\section{History}

$\mathrm{He}$ is the second child from third properly administrated pregnancy. There were not earlier congenital anomalies in family. During a routine sonography in the $37^{\text {th }}$ week of pregnancy, dilatation of the cerebral ventricleswas noted with no other fetal disturbances. After birth,

Correspondence to: Aleksandra Zdravković, M.D.

Clinic of Neurosurgery, Clinical Center of Serbia,

University of Belgrade, Belgrade, Serbia

Phone: +381640103013

E-mail: sandrazdr2@gmail.com

Received November $9^{\text {th }}, 2018$, Accepted December $25^{\text {th }}, 2018$ turribrachycephalywas apparent, but also large bulging anterior fontaneland palpable calvarial defects. No other anomalies were noted, except high-arched palate.

\section{Operation}

At that time, the 3-months-old boy was admitted with clinical signs of hydrocephalus and turribrachycephaly. Computed tomography (CT) showed extremely dilatated cerebral ventricles, all sutures were wide open and the bone was extremely thin due to the raised intracranial pressure. So, during the same hospitalization, in December 2006, ventriculo-peritoneal shunt (VP shunt) with programable valve was implanted to treat the hydrocephalus. The child recovered well after surgery. With addressing the hydrocephalus, time has been given for bone ossification and reduction of the size of bone defects so the remodeling can be done (Figs. 1-2).

In May 2017, posterior calvarial remodeling was done. The bone covering the posterior fossa was completely removed followed by bilateral osteotomies $1 \mathrm{~cm}$ posterior to the coronal suture. The bone band approximately $2 \mathrm{~cm}$ wide was removed and repositioned to reconstruct the occiput. Following this, the remaining parietal and occipital bone was divided in two pieces and rotated to create adequate cranial shape. All bone pieces were fixed using 2.0 absorbable surgical sutures. With this, decompression of posterior cranial segment was done as well as remodeling of the calvarium.The child recuperated well after surgery.

In October 2017, final surgical procedure was performed, an anterior calvarial remodeling.Using the same incision of the previous surgery, frontal bone was exposed just below supraorbital ridges bilaterally. After bilateral osteotomy at the coronal suture and $1.5 \mathrm{~cm}$ 


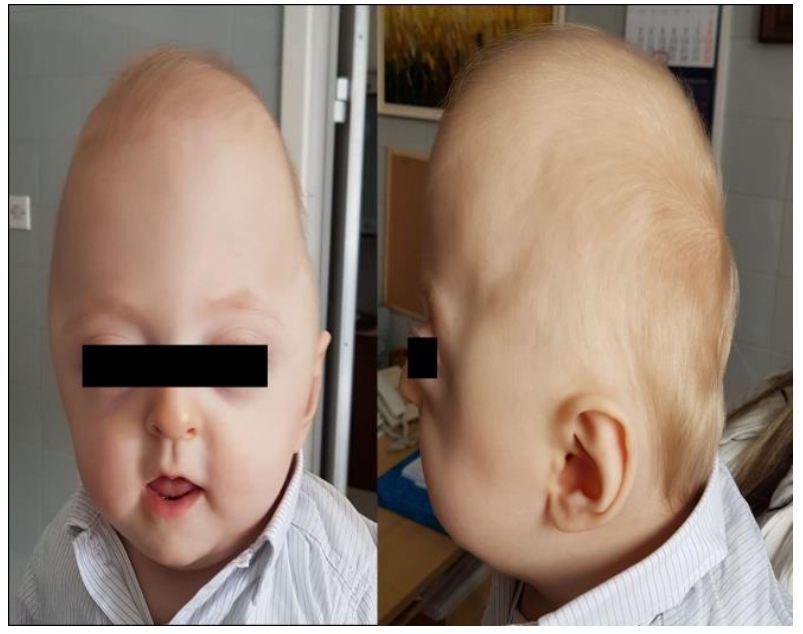

Fig. 1 Photographs of the child before first reconstruction surgery

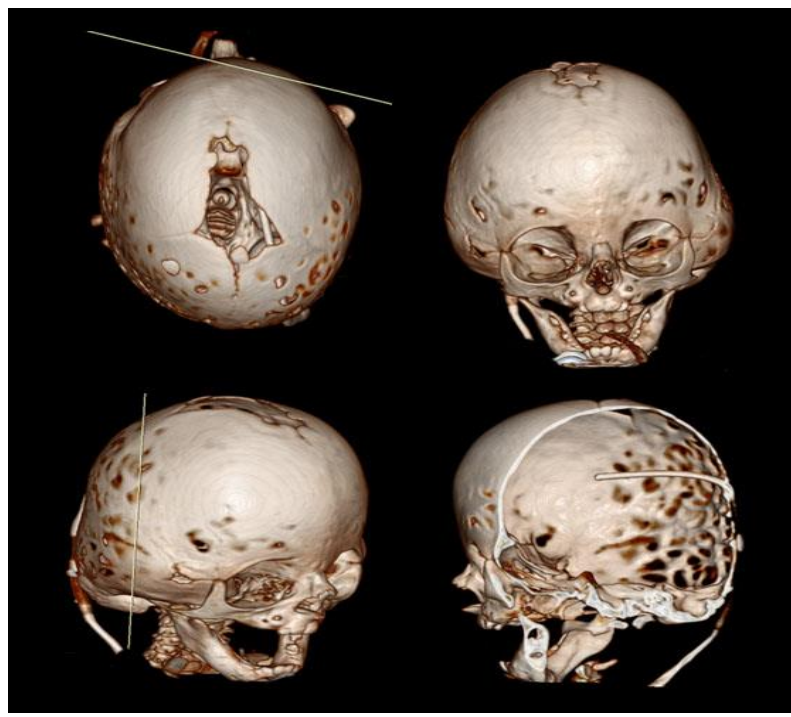

Fig. 2 Preoperative CT three-dimensional bone reconstruction showing complex head deformity and position of the ventricular catheter and valve

above supraorbital margin of the frontal bone, the frontal bone was elevated in one piece. Then, frontoorbital bandeau was made followed by fronto-orbital advancement. The bone was advanced for approximately $2 \mathrm{~cm}$ and fixed using resorbable plates and screws.

\section{Post-operation period}

This completed the calvarial remodeling in this patient (Figs. 3-4). Child is doing well so far, completing milestones of child development in time. Facial advancement is due to be done after the child is approximately 6 years old.

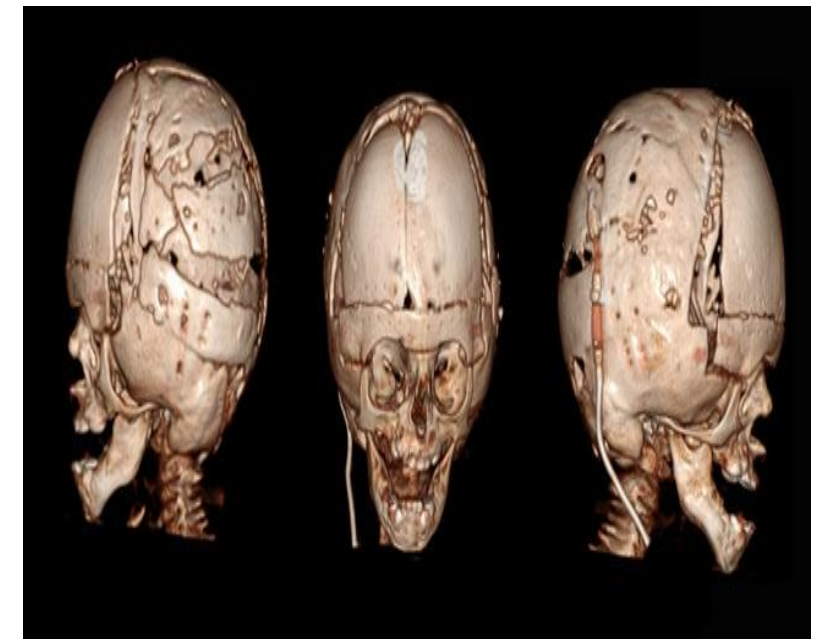

Fig. 3 Postoperative CT three-dimensional bone reconstruction showing entire calvarial remodeling and corrected shape

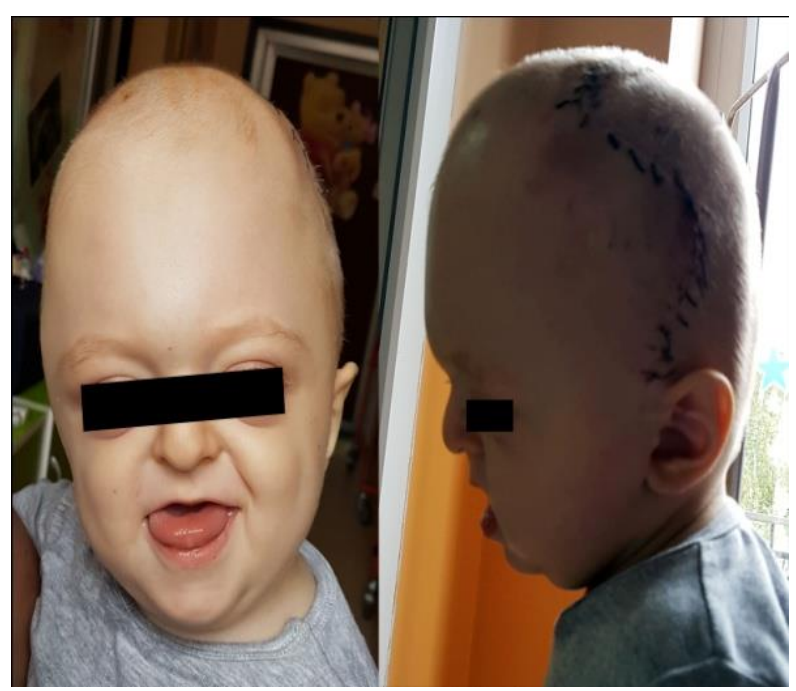

Fig. 4 Photographs of the child on the second postoperative day, showing immediate excellent results

\section{Discussion}

In the literature so far, numerous surgical techniques have been described to treat this complex craniosynostosis. Usually, the patient needs several surgeries to attain good results.

To achieve posterior decompression and remodeling, some authors consider that craniectomy of the posterior fossa is enough [5]. Others, expand entire posterior part of the calvarium using springs or distractors [6]. However, using this technique is creating a need for additional surgery, to remove the distracters and springs, thus additionally complicating the treatment course. Design and size of craniotomy are planned according to wanted gain and shape.

Simultaneous forehead remodeling and fronto-orbital advancement is performed to deal with anterior calvarial deformity [8]. 
Later in life, facial reconstruction needs to be done since the maxilla, nasal complex, and zygomatic body are hypoplastic and the orbits are shallow. These deformities lead to functional problems that may include airway obstruction (up to $50 \%$ of these patients may have sleep apnoea) [8], exorbitism with corneal ulceration, and lid dislocation.

Using the distraction osteogenesisthe mid-face advancement can be achieved. The technique is carried out with monobloc distraction in younger children (less than 2 years of life) and Le Fort III osteotomies and distraction in age 6-10 [9].

Sometimes the treatment course can be simpler. Thompson et al.describeda Crouzon syndrome case, where only occipital cranial vault advancement and decompression was done. Several years later, only the facial correction was necessary [10].

De Jong et al. recommended only fronto-orbital advancement [11]. Jeevanetal. consider a posterior de-

\section{References}

1. Al-Namnam NM, Hariri F, Thong MK, Rahman ZA. Crouzon syndrome: Genetic and intervention review. J Oral Biol Craniofac Res 2019; 9:37-39.

2. Winn R. Youmans and Winn neurological surgery. 7th ed. 2017, Philadelphia, PA Elsevier.

3. Kalanjiam V, Manoharan GVMG. Crouzon syndrome - A rare case report. Int J Health Sci (Qassim) 2017; 11:74-75.

4. Balyen L, Deniz Balyen LS, Pasa S. Clinical characteristics of Crouzon syndrome. Oman J Ophthalmol 2017; 10:120-122.

5. Cinalli G, Chumas P, Arnaud E, Sainte-Rose C. Renier D. Occipital Remodeling and Suboccipital Decompression in Severe Craniosynostosis Associated with Tonsilar Herniation. Neurosurg 1998; 42:66-73.

6. Ong J, Harshbarger R, Kelley P, George T. Posterior Cranial Vault Distraction Osteogenesis: Evolution of Technique. SeminPlast Surg 2014; 28:163-178.

7. Taylor JA, Bartlett SP. What's New in Syndromic Craniosynostosis Surgery? Plastic and Reconstructive Surg 2017; 140:82e-93e. compression as primary treatment and suggest that the fronto-orbital advancement is recommended for the Crouzon syndrome cases without midface hypoplasia [12].

In our presented case, after dealing with hydrocephalus, we performed firstly posterior decompression and later anterior calvarial remodeling. Decompression was achieved and shape of the skull was satisfactory. Since the patient still has no significant airway obstruction, we decided on the delayed timing for mid-face advancement.

\section{Conclusion}

This case presents an extremely complex case of syndromic multisuture craniosynostosis, in which it was necessary to perform the entire calvarial remodeling to correct the deformity and to provide a chance to the brain to grow and develop without constrictions.

8. Pijpers M, Poels PJ, Vaandrager JM, de Hoog M, van den Berg S, HoeveHJ, Joosten KFM. Undiagnosed obstructive sleep apnea syndrome in children with syndromalcraniofacial synostosis. J CraniofacSurg 2004; 15:670-674.

9. Heggie AA, Kumar R, Shand JM. The role of distraction osteogenesis in the management of craniofacial syndromes. Ann Maxillofac Surg 2013; 3:4-10.

10. Thompson D, Jones B, Hayward R, Harkness W. Assessment and treatment of craniosynostosis. Br J Hosp Med 1994; 52:17-24

11. De Jong T, Bannink N, Bredero-Boelhouwer HH, van Veelen ML, Bartels MC, Hoeve LJ, Hoogeboom AJ, Wolvius EB, Lequin MH, van der Meulen JJ, van Adrichem LN, Vaandrager JM, Ongkosuwito EM, Joosten KF, Mathijssen IM. Long-term functional outcome in 167 patients with syndromic craniosynostosis; defining a syndrome-specific risk profile. J Plast Reconstr Aesthet Surg 2010; 63(10):1635-1641.

12. Jeevan DS, Anlsow P, Jayamohan J. Abnormal venous drainage in syndromic craniosynostosis and the role of CT venography. Childs Nerv Syst 2008, 24:1413-1420. 